\title{
Association of placental position with the development of hypertension in pregnancy
}

\author{
Prathima A.*, Reddi Rani P.
}

Department of Obstetrics and Gynecology, Mahatma Gandhi Medical College and Research Institute, Puducherry, India

Received: 25 October 2018

Accepted: 13 December 2018

\section{*Correspondence:}

Dr. Prathima A,

E-mail: Prathima.anand@gmail.com

Copyright: () the author(s), publisher and licensee Medip Academy. This is an open-access article distributed under the terms of the Creative Commons Attribution Non-Commercial License, which permits unrestricted non-commercial use, distribution, and reproduction in any medium, provided the original work is properly cited.

\section{ABSTRACT}

Background: Hypertensive disorders remain the most common medical complication during pregnancy and contribute greatly to maternal and perinatal morbidity and mortality. Several tests have been proposed to identify the women at risk of developing hypertension. Among the various predictors, the placental location by USG at 18-24 weeks is cost effective, non- invasive and has a good positive predictive value. The present study was undertaken to predict the association of placental location with the development of hypertension in pregnancy.

Methods: This was a longitudinal cohort study conducted on 380 uncomplicated primigravid women who attended the obstetric OPD of MGMC\&RI over a period of 18 months (March 2017-august 2018). A detailed history was taken, and examination done and B.P. was measured. The placental location was determined by ultrasound at 18-24 weeks and the patients were divided into two groups : group A were women with lateral placenta and group B were women with other placental locations. All women were followed up for signs and symptoms of hypertensive disorders of pregnancy and mode of delivery and neonatal outcome were noted.

Results: Out of 380 women, 56(14.7\%) had lateral placenta and 324(85.3\%) had other placental locations. Out of the 57 women who developed hypertensive disorders in pregnancy, 16(28.6\%) had lateral placenta and $41(12.7 \%)$ had other placental locations. The risk of developing hypertension in pregnancy with lateral placenta was 3.5(odds ratio) with a $95 \%$ confidence interval (1.4-8.6). The sensitivity, specificity, positive predictive value and negative predictive value when placental laterality is used as a predictive test was $28.1 \%, 87.6 \%, 28.6 \%$ and $87.4 \%$ respectively.

Conclusions: The placental laterality as determined by ultrasound at 18-24 weeks is a simple, non-invasive, costeffective predictive test to predict women at high risk of developing hypertensive disorders of pregnancy and this test has a high specificity and negative predictive value.

Keywords: Hypertension, Placental laterality, Preeclampsia, Ultrasound

\section{INTRODUCTION}

Hypertensive disorders remain the most common medical complication during pregnancy and they complicate up to $10 \%$ of pregnancies worldwide. ${ }^{1}$ They contribute greatly to maternal and perinatal morbidity and mortality. Preeclampsia (PE) is the leading cause which contributes to $50,000-60,000$ deaths per year. ${ }^{2,3}$ The term hypertension in pregnancy is commonly used to describe a wide spectrum of patients who may have only mild elevation in blood pressure or severe hypertension with multiorgan dysfunction. Pregnancy can induce hypertension in normotensive women (or) aggravate already existing hypertension. Infants of women with pregnancy induced hypertension have a five- fold increase in mortality compared to normotensive women. This has led to the interest in screening to prevent these complications by timely prediction. 
Several tests have been proposed to identify the women at risk of developing hypertension. But, none of them are reliable and sensitive. Placental location has been found to correlate with the presence of PE and adverse pregnancy outcome. ${ }^{4}$ There is a significant association between placental location and uterine artery resistance and adverse outcomes such as PE and intrauterine growth retardation (IUGR). If placenta is situated centrally both uterine arteries demonstrate similar resistance, but if placenta is situated laterally, the uterine artery close to the placenta has lower resistance than the opposite one. So, in laterally located placenta, the uteroplacental blood flow is primarily met by one of the uterine arteries with some collateral circulation from the other uterine artery. So, if there is a deficient collateral circulation, women are prone to develop preeclampsia or IUGR or both. ${ }^{5}$ Among the various predictors for hypertension, the placental location by USG at $18-24$ weeks is non- invasive, has a good positive predictive value and is also cost effective. ${ }^{6}$ The present study was undertaken to correlate the association of placental location with the development of hypertension in pregnancy and perinatal outcome.

\section{METHODS}

This longitudinal cohort study was conducted at Mahatma Gandhi medical college and research institute, a tertiary care hospital in Pondicherry. After the approval of the institutional medical ethics committee, the study was conducted from March 2017 to August 2018. A detailed history, general, systemic and obstetric examination was done, blood pressure was measured in sitting position and korotkoff $\mathrm{V}$ sound was taken to determine diastolic component. Ultrasound was done at 18-24 weeks to determine the location of placenta and the patients were divided into 2 groups. Group A was when
$75 \%$ or more of placenta was to one side of midline and it was classified as lateral placenta, Group B was anterior, posterior and fundal placenta. These patiemts were followed till delivery for the development of hypertensive disorders of pregnancy, severity of hypertension was determined, development of other complications like IUGR and preterm birth was noted, mode of delivery and birth weight of the neonate was studied.

\section{Inclusion criteria}

- 380 uncomplicated primigravidas who attended the antenatal outpatient department.

\section{Exclusion criteria}

- Women who were elderly primi, who had teenage pregnancy.

- Women with family h/o hypertension, twin gestation, uterine anomalies, h/o autoimmune disease, h/o antiphopholipid antibody syndrome, thyrotoxicosis, $\mathrm{h} / \mathrm{o}$ connective tissue disorders and renal disease.

\section{Statistical analysis}

Descriptive data was analyzed by using percentage, mean and standard deviation. Inferential data was analyzed using chi square test, odds ratio, sensitivity, specificity, positive predictive value and negative predictive value.

\section{RESULTS}

There was no difference in the baseline characteristics like age and weight among the two groups. Out of 380 women, $56(14.7 \%)$ had lateral placenta (group A) and $324(77.3 \%)$ had other placental locations (group B).

Table 1: Gestational age at development of hypertension in association with placental location.

\begin{tabular}{|l|l|l|l|l|l|}
\hline Groups & Placental position & $28-32$ weeks & $33-36$ weeks & $>36$ weeks & Total \\
\hline Group A & Lateral & $1(6.3)$ & $9(56.30)$ & $6(37.5)$ & 16 \\
\hline \multirow{3}{*}{ Group B } & Fundal & $1(11.1)$ & $5(55.6)$ & $2(33.3)$ & 9 \\
& Anterior & $3(25.0)$ & $3(25.0)$ & $6(50.0)$ & 12 \\
\cline { 2 - 6 } & Posterior & $2(10.0)$ & $8(40.0)$ & $10(50.0)$ & 20 \\
\cline { 2 - 7 } & Total & 7 & 25 & 25 & 57 \\
\hline
\end{tabular}

Pearson chi square value $=4.7, \mathrm{P}$ value $=0.59$

Most of the patients (87.8\%) developed hypertension after 33 weeks. When comparing the gestational age at development of hypertension and placental location, there was no statistical significance. A total of 57 patients developed hypertension, out of which 16 had lateral placenta and 41 had placenta in other locations. There was a significant association between placental position and development of hypertension. Women with lateral placenta had a 3.5 times (odds ratio) greater risk of developing hypertension (Table 2). 
Table 2: Number of patients who had hypertension in the various placental locations.

\begin{tabular}{|l|l|l|l|l|l|}
\hline Groups & Placental position & Total & GHTN-yes & GHTN-No & Odd ratio with 95\% CI \\
\hline Group A & Lateral & 56 & $16(28.6)$ & $40(71.4)$ & $3.5(1.4-8.6)$ \\
\hline \multirow{3}{*}{ Group B } & Fundal & 88 & $9(10.2)$ & $79(89.8)$ & 1 (reference) \\
\cline { 2 - 6 } & Anterior & 112 & $12(10.7)$ & $100(89.3)$ & $1.1(0.4-2.6)$ \\
\cline { 2 - 6 } & Posterior & 124 & $20(16.1)$ & $104(83.9)$ & $1.7(0.7-3.9)$ \\
\cline { 2 - 6 } & Total & 380 & 57 & 323 & \\
\hline
\end{tabular}

Chi square= $11.4 \mathrm{P}$ value: 0.01

Table 3: Number of patients who developed gestational hypertension, preeclampsia and eclampsia among the various placental locations.

\begin{tabular}{|c|c|c|c|c|c|}
\hline & Group A & \multicolumn{4}{|l|}{ Group B } \\
\hline & Lateral n (\%) & Fundal n (\%) & Anterior n (\%) & Posterior n (\%) & Total \\
\hline GHTN only & $13(81.3)$ & $8(88.9)$ & $11(91.7)$ & $13(65.0)$ & 45 \\
\hline Pre-eclampsia & $3(18.7)$ & 0 & $1(8.3)$ & $7(35.0)$ & 11 \\
\hline Eclampsia & 0 & $1(11.1)$ & 0 & 0 & 1 \\
\hline Total & 16 & 9 & 12 & 20 & 57 \\
\hline
\end{tabular}

Preeclampsia was more common with posterior placenta and there was 1 case of eclampsia and the placenta was fundal in that patient. But this was not statistically significant.

The sensitivity, specificity, positive predictive value and negative predictive value when using placental laterality as a predictive test was $28.1 \%, 87.6 \%, 28.6 \%, 87.4 \%$ respectively (Table 4).

Severe hypertension was more common in patients with posterior placenta, but this was not statistically significant. IUGR was more common among women with posterior placenta and one woman from every placental location had preterm birth.
Table 4: Sensitivity, specificity, positive predictive value, negative predictive value.

\begin{tabular}{|l|l|l|l|}
\hline Placental position & GHTN-Yes & GHTN-No & Total \\
\hline Lateral (Group A) & 16 & 40 & 56 \\
\hline $\begin{array}{l}\text { Other position } \\
\text { (Group B) }\end{array}$ & 41 & 283 & 324 \\
\hline Total & 57 & 323 & 380 \\
\hline
\end{tabular}

There was no statistical significance when placental location was studied with IUGR and preterm labor. Mode of delivery and neonatal weight had no statistical significance when they were studied with placental location (Table 5).

Table 5: Severity of hypertension based on diastolic blood pressure in relation to placental location.

\begin{tabular}{|c|c|c|c|c|c|}
\hline & Group A & Gro & & & \\
\hline Severity of GHTN & Lateral n (\%) & Fundal n (\%) & Anterior n (\%) & Posterior n (\%) & Total \\
\hline Mild & $5(19.2)$ & $5(19.2)$ & $8(30.8)$ & $8(30.8)$ & 26 \\
\hline Moderate & $9(45.0)$ & $3(15.0)$ & $3(15.0)$ & $5(25.0)$ & 20 \\
\hline Severe & $2(18.2)$ & $1(9.1)$ & $1(9.1)$ & $7(63.6)$ & 11 \\
\hline Total & 16 & 9 & 12 & 20 & 57 \\
\hline
\end{tabular}

Pearson chi square value $=9.2, \mathrm{P}$ value $=0.16$

\section{DISCUSSION}

Hypertensive disorders of pregnancy are a group of disorders which constitute a complex clinical syndrome and are the leading cause of maternal and perinatal mortality and morbidity. ${ }^{5}$
Thus, there is an increased need for a screening test which can predict the occurrence of hypertensive disorders in pregnancy. Various screening tests are available but none of them have given promising results.

Placental location as seen by ultrasound at 18-24 weeks has proven to be a simple and cost-effective method for 
the prediction of hypertensive disorders in pregnancy. In the present study, placental location was divided as lateral, anterior, posterior and fundal as determined by ultrasound and the incidence of hypertensive disorders in the respective groups was studied to determine if placental location can be used as a predictor of hypertensive disorders of pregnancy.

In the present study, out of 380 women, 57 had hypertension in pregnancy, out of which 16 (28.6\%) had lateral placenta and $41(12.7 \%)$ had other placental locations. Most of the patients $(87.8 \%)$ developed hypertension after 33 weeks. This finding was consistent to the study done by Kannamani et al. ${ }^{7}$

The overall risk of developing hypertensive disorders of pregnancy was found to be 3.5 times (odds ratio) more with lateral placenta in this study.

When the placenta is central, uteroplacental blood flow needs are met by equal contribution from both uterine arteries as both uterine arteries have similar resistance whereas in laterally situated placenta the needs are met primarily by one of the uterine arteries and there is some contribution from the other uterine artery via collateral circulation.

However, this collateral circulation may not be the same and the inadequate contribution leads to the development of hypertensive disorders, IUGR or both. ${ }^{5}$ There is reduced trophoblastic invasion in laterally situated placenta due to less uteroplacental blood flow which is the primary inciting factor for the development of PE. This in turn can cause uteroplacental insufficiency and IUGR. $^{8}$

These results were comparable to the study done by Nandanwar et al who stated that the risk of developing hypertension in pregnancy was 3.45 times more with lateral placenta. ${ }^{9}$

The sensitivity, specificity, positive predictive value and negative value when using lateralization as a screening test were $28.1 \%, 87.6 \%, 28.6 \%$ and $87.4 \%$ respectively. The specificity and negative predictive value are good in the present study and placental position is an easy, non invasive test to predict hypertensive disorders. Similar finding was reported by Kore et al who reported the sensitivity, specificity, positive predictive value and negative predictive value is $59.38 \%, 88.10 \%, 48.72 \%$ and $91.93 \%$ respectively. ${ }^{10}$

While assessing the severity of hypertension depending on the diastolic blood pressure in the various locations of placenta, it was found that more number of women with posterior placenta had severe hypertension which is at variance to the studies done by Nandanwar et al who found that severity of hypertension was more in women with lateral placenta. ${ }^{9}$ This might be because the number of women with posterior placenta were more in this study.

In the present study, among 11 patients who developed preeclampsia, 7 had posterior and 1 patient who developed eclampsia had fundal placenta. This is in contrast to the study done by Jaiswal et al who observed preeclampsia and eclampsia to be more common in the women with lateral placenta. ${ }^{11}$

However, Magann et al reported that development of PE has no relationship to the placental location. ${ }^{12}$ In this study 10 women had IUGR, out of which 6 had posterior placenta, 2 had anterior placenta, 1 had fundal and 1 had lateral placenta. However, Magann et al reported that presence of IUGR was not influenced by placental location. $^{12}$

In a study done by Magann et al they found that preterm labor was more common with low implantation of placenta and has no relation with placenta implanted high in the uterus. ${ }^{12}$ The finding of this study was similar in which 4 patients had preterm labor ie; there was one patient in lateral group and three patients in the other placental groups and this was not statistically significant. In this study, there was no difference in birth weight and mode of delivery. Similar was the observation by Bhalerao et al and Jaiswal et al. ${ }^{11,13}$

\section{CONCLUSION}

The placental laterality as determined by ultrasound at 18-24 weeks is a simple, non-invasive, cost-effective predictive test to predict women at high risk of developing hypertensive disorders of pregnancy and this test has a high specificity and negative predictive value. Furthermore, this test does not require any extra testing as the placental location can be determined when anomaly scan is being done. Combining uterine artery Doppler studies with placental location has a higher predictive value, which has not been done in this study and is a limitation of this study.

\section{Funding: No funding sources}

Conflict of interest: None declared

Ethical approval: The study was approved by the Institutional Ethics Committee

\section{REFERENCES}

1. American College of Obstetricians and Gynecologists, and Task Force on Hypertension in Pregnancy, Hypertension in pregnancy. Report of the American College of Obstetricians \& Gynecologists' Task Forceon Hypertensionin Pregnancy, Obstetrics and Gynecology, 2013:122(5):1122-31

2. World Health Organization, Make Every Mother and Child Count,World Health Report, 2005, World Health Organization, Geneva,Switzerland,2005. 
3. Duley L. Maternal mortality associated with hypertensive disorders of pregnancy in Africa, Asia, Latin America and the Caribbean. BJOG Int J Obstet Gynaecol. 1992;99(7):547-53.

4. Chapman MG, Furness ET, Jones WR, Sheat JH. Significance of the ultrasound location of placental site in early pregnancy. BJOG Int J Obstet Gynaecol. 1979;86(11):846-48.

5. Van Beek E, Peeters LLH. Pathogenesis of preeclampsia: a comprehensive model. Obstet Gynecol Surv. 1998;53(4):233-39.

6. Cunningham FG, Leveno KJ, Bloom SL, et al. Hypertensive disorders. In: Williams obstetrics. 22nd ed. New York: McGraw-Hill; 2005. p. 761-808

7. Kannamani A, Narasimhan D. A study on analysis of validity of lateral placental location in prediction of preeclampsia. J Evol Med Dent Sci-JEMDS. 2017;6(18):1401-03.

8. North RA, Ferrier C, Long D, Townend K, KincaidSmith P. Uterine artery Doppler flow velocity waveforms in the second trimester for the prediction of preeclampsia and fetal growth retardation. Obstet Gynecol. 1994;83(3):378-86.

9. Nandanwar RA, Wahane AM, Dange NS. The Relation between development of Pregnancy Induced
Hypertension and location of placenta among the pregnant women in Bastar Region. Indian J Clin Anat Physiol. 2015;2(4):169-73.

10. Kore SJ, Khot R, Supe P, Kanavia D, Thunga C, Nandanwar Y. Prediction of pre-eclampsia: role of placental laterality by ultrasonography. Int J Reprod Contracept Obstet Gynecol. 2016;5(5):1433-7.

11. Jaiswal J, Jaiswal A, Nagaria T, Ramteke A. Prediction of pregnancy induced hypertension by USG guided placental localization. J Evol Med Dent Sci-JEMDS. 2015;4(81):14163-72.

12. Magann EF, Doherty DA, Turner K, Lanneau Jr GS, Morrison JC, Newnham JP. Second trimester placental location as a predictor of an adverse pregnancy outcome. J Perinatol. 2007;27(1):9-14.

13. Bhalerao AV, Kukarni S, Somalwar S. Lateral placentation by ultasonography: a simple predictor of preeclampsia. J South Asian Feder Obst Gynae. 2013;5(2):68-71.

Cite this article as: Prathima A, Reddi Rani P. Association of placental position with the development of hypertension in pregnancy. Int $\mathbf{J}$ Reprod Contracept Obstet Gynecol 2019;8:238-42. 